\title{
IMPACTO SOCIAL DE UN PROGRAMA SOCIOEDUCATIVO EN MEDIO ABIERTO: ALDEAS INFANTILES SOS Y LOS CENTROS DE DÍA DE ATENCIÓN A MENORES
}

\author{
Juan Manuel Sánchez Ramos \\ Aldeas Infantiles SOS España
}

RESUMEN: Este trabajo revela la influencia social que, los centros de día de atención a menores en poblaciones de exclusión social, ejercen sobre el entorno, concretamente sobre sus agentes sociales, desde la Asociación de Aldeas infantil SOS. Sin pretenderlo directamente, esta influencia social trae consigo unos efectos colaterales de concientización en los principales agentes implicados como políticos, empresarios, profesores y vecindario.

PALABRAS CLAVE: Influencia social, desarrollo socio comunitario, exclusión social.

\section{SOCIAL IMPACT OF A SOCIOEDUCATIVE PROJECT: SOS KINDERDORF INTERNATIONAL AND MINOR DAY-CARE CENTERS}

\begin{abstract}
This work shows the social influence that exclusion social minor day-care centers apply over the context or environment, specifically over the social agents, from SOS Kinderdorf International. Without expect, this social influence improves the understanding of the different social agents as political, police, business man, teachers and neighborhood.
\end{abstract}

KEYWORDS: Social influence, socio-community development, exclusion social.

Recibido: 14/10/2012

Aceptado: 17/08/2013 


\section{INTRODUCCIÓN}

Cuando nos referimos a personas en circunstancias de vulnerabilidad social, interesa conocer estrategias que faciliten sus cometidos y apoyen a los profesionales encargados de paliar o dar respuesta a tales situaciones. Los programas socioeducativos, en cierta medida, tienen que transcender fuera del espacio de acción y personas a las que se dirigen esparciendo sus efectos hacia el entorno circundante (escuela, familia, servicios públicos y privados...). Entendemos que un modelo de educación social ha de ser capaz de generar nuevas oportunidades de desarrollo socio-comunitario en la voluntad de conciliar el viejo debate entre el binomio individuo y sociedad.

La pretensión del estudio que nos ocupa es demostrar que los programas que se implementan en los centros de día de atención a menores sostienen capacidades de transformación en la comunidad en general y de los agentes sociales en particular, más allá de la situación social de sus beneficiarios. Ante situaciones extremas que merodean los límites de la marginalidad y la inadaptación, tanto el entorno social como los mediadores de la socialización, en ocasiones se ven desbordados e impotentes para hacer frente a dichas adversidades. No es extraño que estas situaciones se acompañen de sentimientos de frustración, desmotivación, derrotismo, actitudes cómplices de la desilusión y la ausencia del ímpetu preciso para el desarrollo eficaz de las funciones profesionales referidas a los agentes sociales. Cabe plantearse si los agentes de una determinada comunidad encuentran registros de apoyo en sus funciones de servicio comunitario, efecto de los comportamientos procedentes de menores, adolescentes y familias en peligro social. Por ello nos preguntamos, ¿cómo incide el comportamiento disruptivo de un adolescente en los docentes, técnicos, policía, políticos, empresarios, vecinos e incluso en la familia? Las posibles respuestas pueden ser variopintas, pero con frecuencia en muchas de esas personas se encuentra oculto un sentimiento de impotencia, involución; el compromiso profesional se convierte en frustración personal y social al sentirse desbordados por el ímpetu de un torrente descontrolado.

\section{Menores, adolesCentes y familias en RiesGo de eXClusión SOCIAL}

El uso constante de los términos, menores, adolescentes y familias en situación de riesgo de exclusión social obliga a identificar sus rostros y sus conductas como manifestación de unas vidas desajustadas y socialmente nubladas.

Respecto a los menores y adolescentes, Castelló et al. (2005), asegura que los niños atendidos en los centros de día, tienen problemas de autoestima y de adaptación familiar, escolar y social. Muchos de ellos presentan déficit en las pautas de socialización que les impiden mantener una relación positiva con los demás y que se manifiestan en problemas de conducta importantes: falta de aceptación personal, bloqueos, comportamientos agresivos, aislamiento, problemas de relación, desconfianza y utilización de la fuerza o la violencia como única respuesta a la resolución de problemas. Otros, ni tan siquiera tienen satisfechas sus necesidades más básicas: alimentación adecuada, condiciones higiénicas, seguridad, etc. La mayoría sufre fracaso escolar, no sigue los contenidos académicos, no posee los materiales educativos necesarios, es absentista y tiene problemas de relación con sus profesores. 
Estamos hablando, en definitiva, de menores en situación de riesgo que necesitan ayuda para aprovechar sus virtudes y potencialidades contrarrestando la oscura realidad en la que se encuentran inmersos, al objeto de evitar la escalada hacia cotas elevadas de marginalidad e inadaptación.

Aunque no es el núcleo principal del estudio, el centro de día también cobija niños que no presentan, tan intensamente, las problemáticas señaladas; están integrados en el conjunto de servicios donde tienen una función compensadora importante en cuanto al proceso de socialización grupal se refiere, ya que desempeñan un papel de referencia positiva y funcionan como barrera contra posibles estigmatizaciones, al tiempo que reciben los beneficios la acción educativa.

La presencia de los rasgos de Castelló representa un cuadro que conduce a la más que probable alteración de la conducta y personalidad del menor y adolescente.

En relación a las familias, Casas (1998), indica que existen personas y familias que debido a las circunstancias que han vivido o viven, tienen más probabilidad de padecer una situación social negativa y esto de por sí les convierte en vulnerables. Del mismo modo, entiende que la vulnerabilidad, se relaciona con la capacidad de pedir ayuda de un sujeto ante determinadas situaciones de crisis personal, familiar o social. Él establece la siguiente clasificación:

- Crisis familiares cuya base radica en dificultades de carácter material o físico; el paro continuado o una enfermedad grave o larga pueden llevar a una crisis. Las familias con recursos humanos limitados son mucho más vulnerables a las mencionadas situaciones (por ejemplo, las familias monoparentales o las familias sobrecargadas de responsabilidades). Cuando el hogar no recibe el apoyo social adecuado, se generan sentimientos adicionales de aislamiento y exclusión social, García Mínguez y Sánchez Ramos (2010). Entonces la crisis puede dar paso a problemas cada vez más graves: agresividad interna, depresión, alcoholismo, drogas, etc.

- Crisis que arrancan de unas relaciones en conflicto con el entorno social circundante: los prejuicios por pertenencia a algún tipo de minoría, el etiquetaje social (ser considerado expresidiario, drogadicto, portador de enfermedades contagiosas, etc.) o el estigma, son ejemplos que pueden llevar a la marginación social. También hay que considerar en este apartado a aquellos socioentornos donde imperan la violencia o las formas de vida estresante o delictiva, por su contribución al malestar psíquico, individual o familiar.

Con base en posicionamientos fenomenológicos hacemos el siguiente planteamiento.

\section{3. ¿Cómo influye esta ReAlidad en los agentes SOCiales Del entORNo?}

\section{¿Quiénes son los agentes sociales?}

Los desequilibrios adscritos a menores, adolescentes y familias extienden el eco con una resonancia negativa en aquellas personas que giran en torno a la vida de dicho segmento de población; la sociología identifica a tales personas como 'agentes sociales'. El concepto de agente social remite a la idea de sociedad plural, abierta a 
la defensa de distintos intereses, complementarios o enfrentados según las características de éstas y del contexto social en el que se ubiquen.

En concreto, ¿quiénes son los agentes sociales vinculados a los centros de día? Para responder a dicha cuestión partimos de una premisa capital: Ios centros de día son programas que se nutren del entorno y permiten que el entorno se nutra de él. Desde el prisma de la fenomenología (Husserl) y del interaccionismo simbólico (Blumer), tenemos presente que los procesos de relación y socialización acontecen en interacción con personas, instituciones y ambientes, entendiendo que cada uno de ellos es responsable del equilibrio y la armonía ciudadana. Comprendiendo que el concepto de 'agente social' es amplio, acotamos para el artículo que nos ocupa su figura a la de los docentes que educan a menores y jóvenes y que mantienen relación con sus familias; empresarios del entorno que ostentan de alguna manera un trato diario con los beneficiarios del programa; políticos que luchan por mejorar el día a día de sus ciudadanos; policía que cuida por la seguridad de los habitantes del municipio; técnicos de servicios sociales que velan por la igualdad de oportunidades y por el bienestar social; vecinos que desean residir en un entorno idóneo que les permita cierta calidad de vida; padres y madres ajenos al centro de día que desean mejorar su situación y especialmente la de sus hijos y por qué no hablar también de los medios de comunicación en su afán por tener informados y unidos a los ciudadanos.

Todas las figuras sociales mencionadas influyen en la cotidianeidad y en el desarrollo personal, social, escolar y familiar de los menores, usuarios del programa educativo, estableciéndose una correlación bidireccional formada por procesos de correspondencia. No es un asunto baladí: la reciprocidad sale al encuentro como obvia consecuencia de comportamientos que se llaman de riesgo; se ponen en circulación experiencias de impotencia, malestar, incertidumbre, inseguridad, por citar algunas emociones que ahora desarrollamos. Vecina y Ballester (2012) apuntan que la relación entre el desarrollo comunitario y el desarrollo de actuaciones sociales y culturales están estrechamente relacionadas en aras del bienestar.

\section{¿Cómo afectan los comportamientos de riesgo?}

Los profesionales que trabajan con menores socialmente vulnerables en su propio medio conocen por experiencia los comentarios que emiten algunos docentes ante sus alumnos: "este es un caso perdido", "¡no se qué más hacer!”, "a mí_no me han preparado para esto", "me está hundiendo la clase", "el día que no viene el aula parece otra", "a sus padres les importa un pimiento la educación de sus hijos; ni siquiera los conozco". Tales expresiones indican, por un lado, la guerra interna de la comunidad socioeducativa, por otro, la carencia de estrategias para abordar las emociones compulsivas, lo que unido a la impotencia y la falta de apoyos unos y otros son engullidos por el derrotismo. En la misma línea determinados empresarios muestran su descontento por el malestar o la mala imagen que genera el colectivo en sus negocios, al sufrir los efectos de actos vandálicos protagonizados por menores.

Análogamente, las personas dedicadas a la política (alcaldes, concejales, oposición, delegados provinciales y autonómicos) reciben la presión de sus ciudadanos solicitando mitigar los problemas de seguridad; se demandan acciones contundentes contra el gamberrismo, no sin antes culpar a los políticos del descontrol de la calle. A 
veces algunos programas electorales dan cuenta de la atención a la infancia en riesgo sin mucho énfasis real. Distintas comisiones municipales se hacen eco del descontento social, pero no es infrecuente descargar la responsabilidad sobre los servicios sociales, si bien estos tampoco tienen armas para establecer la convivencia, entre otros motivos, porque su propio sistema de trabajo no está preparado para la prevención. Siendo el suyo un trabajo de protección, solo intervienen cuando los problemas ofrecen un ambiente intolerable, dando como resultado en numerosas ocasiones la actitud represiva protagonizada por la propia policía local.

A las fuerzas de seguridad sólo preocupan los comportamientos de emergencia que exhiben los menores y adolescentes. La policía hace frente al absentismo escolar, a la violencia, al vandalismo, a las negligencias de tráfico, robos y hurtos y otros comportamientos disruptivos de la paz social. La relación existente entre policía y menores es evasiva, culpando a otros, "todo esto es porque alguien no hace su trabajo eficazmente", "a las familias les da igual lo que hagan" o represiva con derecho al juicio condenatorio: "el único ocio que tienen es beber y fumar en la plaza, tirar piedras y buscarse a alguien con el que descargar su ira, y de ahí no salen". Asimismo, a padres y madres les inquietan el futuro y los círculos sociales que frecuentan sus hijos pero se encuentran incapaces de explorar un modelo educativo que evite mayores riesgos.

A nuestro entender, existen alternativas esperanzadoras capaces alcanzar importantes beneficios para la comunidad, padres, hijos y especialmente los agentes sociales, pero ¿de dónde procede esa esperanza?

\section{Afrontamiento de las conductas de riesgo: el programa educativo DE LOS CENTROS DE DíA DE ATENCIÓN A MENORES}

\section{¿De qué hablamos cuando nos referimos a los centros de día dirigidos a menores?}

Según Eliécer Rosinach, (2005: 1), un centro abierto “... es un espacio educativo dirigido a niños y adolescentes que conviven en su domicilio con su familia. Por tanto, generalmente se trata de un tipo de intervención preventiva. Para ser considerado centro abierto, este espacio debe reunir los siguientes requisitos: periodicidad diaria, equipo educativo estable, necesidad de intervención socioeducativa por parte de los niños, compromiso de asistencia diaria y oferta de una intervención educativa integral". El primer elemento que encontramos en la definición de Rosinach es el educativo. Este será el medio para prevenir o paliar situaciones de riesgo que dificultan o dificultarán la integración social del menor. Por tanto, entendemos los centros de día o centros abiertos, como espacios educativos que favorecen la integración del menor desde la situación de vulnerabilidad en la que se encuentran. El segundo componente de la definición de Rosinach alude a los destinatarios: menores y adolescentes que conviven en su domicilio con su familia. Entendemos consiguientemente que la finalidad de los centros de día, es desarrollar acciones y programas que eviten el internamiento del menor y la separación de su familia biológica y de su entorno. Como

1. En algunas comunidades autonómicas, (principalmente Cataluña) los centros de día se conocen también como centros abiertos. 
bien dice, es un tipo de intervención preventiva_que evita y disminuye los indicadores de riesgo que rodean al menor en sus distintas dimensiones: familiar, social y escolar.

Podríamos resumir el apartado estructurando los conceptos expuestos: a) un marco de desarrollo temporal: servicio diurno y fuera del horario escolar. Por lo que enmarcamos el programa en el ámbito de la educación no formal. b) unas áreas de acción: la personalidad, la socialización, la adquisición de aprendizajes básicos y la compensación de las carencias socioeducativas que ha de cubrir el recurso respecto a los usuarios.

\section{Programa marco}

Apuntada la identificación de los centros de día para menores resulta obligado presentar una alternativa a las enturbiadas relaciones sociales. El programa marco tiene presente la formación de la persona para vivir en comunidad en base a las interacciones producidas con otros individuos y en distintas situaciones (Sánchez Ramos, 2012). Bien sabemos que el centro de día es un proyecto dirigido a menores y familias socialmente vulnerables derivados por los servicios sociales comunitarios de la zona; en ellos, no solo se atiende a las personas, sino que se estimula la inclusión y participación social a partir de diferentes actividades educativas fuera del horario escolar. Veíamos que la finalidad básica del planteamiento educativo era evitar la separación del menor de su entorno natural de desarrollo, por ello, es por lo que las actividades se centran en las esferas familiar, escolar, social y personal, puesto que es necesario abordar la problemática de forma integral. Los objetivos principales por los cuales se gobiernan todas nuestras acciones, giran en torno a:

1. Atender a menores, jóvenes y familias en peligro social, procurándoles la integración a la vida de la ciudad.

2. Ofrecer la ayuda educativa y formativa necesaria a la infancia y la juventud para la mejora de sus aptitudes personales, rendimiento escolar y aprovechamiento de los momentos de ocio y tiempo libre.

3. Compensar las deficiencias socio-educativas registradas en el entorno y personalizadas en los 'agentes sociales'.

4. Capacitar a las familias con problemas y carencias socio-educativas para el pleno progreso de sus responsabilidades y capacidades en relación con sus hijos y el entorno.

Para el logro de estos objetivos el programa se vale de unas estrategias que rondan los distintos planos de crecimiento de los menores, articulándose entre sí. Veamos cuáles son:

\section{Actuaciones programadas}

Sin querer caer en un activismo aleatorio y sin rumbo, las estrategias socioeducativas planteadas responden al logro de un ideal educativo fundado en los posicionamientos filosóficos existencialistas de Heidegger y del interaccionismo simbólico de Blumer: tiene prioritario sentido buscar la formación del 'ser' para 'estar' en el mundo, y como apuntábamos anteriormente, dicho aprendizaje se despliega con base en una mirada multidimensional: 
a) Actuaciones vinculadas a la formación, capacitación y sensibilización de las familias respecto a la educación y la crianza de sus hijos

La familia, como primer agente de socialización del niño, estará equipada para el desempeño de su misión educativa. Nuestra oferta se ciñe a la promoción y al ajuste en sus responsabilidades como padres y madres, estableciéndose elementos de formación y capacitación.

b) Acciones concernidas al rendimiento académico

Desde este ámbito, se da cobertura a las carencias y déficits de los menores en el contexto académico. Reducir el absentismo y el fracaso escolar, disminuir las conductas disruptivas, elevar la motivación de los menores e implicar a las familias en la vida escolar de sus hijos son fijaciones en las que se centran las actividades dirigidas al plano escolar.

c) Estrategias que favorecen la mejora y la adquisición de competencias sociales, con énfasis en la participación ciudadana

Las relaciones sociales positivas con personas e instituciones del entorno es considerado como un factor esencial para disminuir los riesgos de exclusión y marginación. Transversalmente, la participación es un factor decisivo para formar parte del 'grupo normativo'. Con estas intenciones abordamos el trabajo abogando por la creación de nuevas vivencias estimuladas desde los juegos populares y tradicionales, acercamiento y uso de los recursos del entorno, participación en las actividades y otros eventos del entorno, fomento de hábitos higiénico saludables, práctica de deportes alternativos y talleres de negociación y resolución de conflictos.

d) Realizaciones encaminadas a la mejora del autocontrol, autoestima y autoconocimiento

Los grandes teóricos en psicología evolutiva, (Piaget, Wallon o Vygotsky) indican que la infancia y la adolescencia son las etapas en las que se reta la construcción de una personalidad del individuo con proyección temporal a lo largo de su vida. Nuestra apuesta es favorecer positivamente dichos parámetros mediante el desempeño de actividades encaminadas a la construcción del yo como sujeto que vive en sociedad.

El programa que hemos presentado carecería de sentido si no fuera por el modo de Ilevarlas a cabo. La metodología es un aspecto crucial que hay que cuidar y seguir escrupulosamente. Brevemente reseñamos que los referidos ámbitos educativos se asientan en cuatro pilares metodológicos básicos: a) la coordinación con todas aqueIlas personas e instituciones que giran en torno a la vida del menor, b) la mediación en la vida diaria para satisfacer las necesidades básicas de los menores y sus familias, c) la vinculación emocional y afectiva necesaria para lograr aquello que algunos autores denominan "autoridad moral" imprescindible en el trabajo con personas en riesgo y d) la implicación de las familias en la vida del centro de día.

A través de la combinación de estrategias y metodología que hemos explicado, vamos a conocer en qué términos los agentes sociales del entorno, donde el programa tiene presencia, modifican su visión personal y laboral reconocida la optimización de los compromisos profesionales. 


\section{Metodología}

Nuestro ámbito de estudio es estrictamente social, donde lograremos confirmar la idoneidad de un recurso a través de la mirada de los agentes sociales. Desde este marco, el racionalismo se configura como un paradigma en el que desde sus postulados filosóficos y metodológicos no da respuesta suficiente para descifrar los entresijos sociales de nuestro objeto de estudio. En palabras de Pérez Serrano (1994: 26) “... en las disciplinas de ámbito social existen diferentes problemáticas, cuestiones y restricciones que no se pueden explicar ni comprender en toda su extensión desde la metodología cuantitativa". Es por ello por lo que seleccionamos el enfoque cualitativo apoyándonos en las siguientes premisas de nuestra investigación:

- Comprender la realidad desde un contexto acotado y determinado: los agentes sociales

- Reflexión crítica de sus experiencias y vivencias frente a la teoría

- Descripción e interpretación de los hechos y aconteceres a través de registros fruto de la observación natural y sin control

- Importancia de las interpretaciones de los participantes sobre los hechos: gestos, sentimientos, comentarios, comportamientos, etc.

- La interacción con los participantes en su medio

Desde el prisma cualitativo se desgajan diversos métodos de interpretación de la información. El estudio se va a centrar en tres procesos que, combinados entre sí, ofrecerán una trilogía metodológica que permitirá explicar los cambios en los agentes sociales. Dicho agrupamiento metodológico se compone de la etnometodología, el interaccionismo simbólico y la fenomenología.

Los agentes sociales que han participado están vinculados, directa o indirectamente, a los centros de día de la ONG Aldeas Infantiles SOS, hallados en las ciudades de Zaragoza, Vigo y Granada. La muestra se circunscribe a 52 agentes sociales, los cuales aportaron información relevante en torno a la evolución social de los menores. Su perfil cualitativo queda descrito en el punto 3 , en la tabla1 plasmamos los datos cuantitativos.

Tabla 1. Agentes Sociales

\begin{tabular}{|l|c|c|c|c|c|c|c|}
\hline \multicolumn{2}{|c|}{ Ciudad } & \multirow{2}{*}{$\boldsymbol{N}^{\boldsymbol{o}}$} & \multicolumn{7}{|c|}{ Agentes Sociales } \\
\cline { 3 - 9 } & & $\begin{array}{c}\boldsymbol{E} \boldsymbol{E} \text {. } \\
\text { Social }\end{array}$ & $\begin{array}{c}\text { Trab. } \\
\text { Social }\end{array}$ & Psicólogo & Orientador & Docentes & Otros \\
\hline Granada & 19 & 6 & 1 & 1 & 2 & 2 & 7 \\
\hline Zaragoza & 17 & 2 & 2 & 1 & 1 & 6 & 6 \\
\hline Vigo & 16 & 1 & 1 & 1 & 2 & 6 & 5 \\
\hline TOTAL & 52 & 9 & 4 & 3 & 5 & 20 & 12 \\
\hline
\end{tabular}

Los instrumentos de recogida de información se entienden en escala de complementación. El registro anecdótico es un instrumento adaptado a las premisas etnometodológicas para conocer en qué términos se lleva a cabo la transformación social de 
las personas. La información acopiada mediante anotaciones de campo es objetiva y fundada desde la subjetividad de los agentes, registrándose información libre, natural y espontánea de las expresiones verbales o gestuales de todos aquellos entes que mantienen alguna relación con el centro. Fruto de la coordinación, encuentros entre los agentes sociales y profesionales del centro de día y como consecuencia de un proceso de observación participante, se ha ido tomando nota de aquellas expresiones que sugerían o aludían a los efectos del programa.

El otro instrumento empleado es la entrevista semiestructurada. Se realizaron a los profesionales en las dependencias de los centros educativos, los servicios sociales, en los centros de día y en otras instancias públicas que tuvimos la oportunidad de visitar. Todas fueron grabadas, originando en la mayoría de las veces, tensión, nerviosismo y distracción en las personas consultadas. Ante una reacción imprevista, estimamos ofrecer dos momentos: a) el que se realiza con presencia de una grabadora y b) el que surge después de finalizar la entrevista con la grabadora inactiva. En ésta última fase fijamos las anotaciones; en sendos espacios nos preocupamos de recoger, por un lado sentimientos, emociones, gestos y por otro, nuevas declaraciones y testimonios sin el estrés y la presión psicológica producida por la grabadora. La duración media de las entrevistas oscilaba entre los 15 y los 25 minutos. Estas consultas han pretendido averiguar en qué medida el programa resulta ser un apoyo para familias, hijos y docentes en su quehacer cotidiano. Así pues, las conductas aparecen en los ámbitos no formales, formales e informales de la educación. Así mismo, entendiendo a los centros de día como un recurso comunitario, es pertinente conocer hasta qué punto complementa y refuerza la labor profesional de los agentes sociales que intervienen en él. Las cuestiones llevadas a cabo han girado en torno a: ¿qué pensáis que aporta el centro de día a los menores y sus familias?; ¿qué le aporta al municipio?; ¿en qué aspectos complementa vuestro trabajo? Con estos interrogantes intentaremos profundizar la incidencia de los programas educativos de los centros de día en nuestra población de estudio.

También nos hacemos eco de algunas noticias publicadas por los medios de comunicación que nos servirán para recoger el alcance mediático del planteamiento educativo que exhibimos.

\section{Resultados y CONCLUSIONES}

\section{Discusión y Resultados}

Al investigar los centros de día de atención a menores, los datos obtenidos a través de las distintas técnicas de recogida de información nos conducen al impacto social, objetivo que al inicio no estaba contemplado. En este sentido, los profesionales de los centros de día de las ciudades de Granada, Zaragoza y Vigo, coincidían en el relato de los difíciles comienzos que tuvieron que atravesar: el impreciso desconocimiento de los vecinos hacia el recurso, la adaptación de los niños y sus familias al programa, las limitaciones técnico-educativas de los profesionales y finalmente el escepticismo generalizado hacia algo nuevo y desconocido por el entorno.

Con el tiempo la valoración del programa fue cambiando en la vecindad y los agentes sociales; la sorpresa llegó a lo más alto cuando observaban que, a diario, 
los niños visitaban libremente las instalaciones para inscribirse, sabiendo que era un sitio donde se alternaba el estudio y el juego. Tras unos meses de andadura, en los servicios sociales comunitarios existían y existen, en los tres centros que analizamos, una lista de espera significativa. Las presiones fueron de tal índole en los ayuntamientos que tuvieron que intervenir y mediar para dar respuesta a las demandas. A escaso tiempo, la visión comunitaria fue cambiando y hoy día el apoyo es generalizado. Al centro acuden madres ajenas al recurso a conocerlo, a comentar los problemas de sus hijos y a pedir consejo para mejorar la dinámica familiar; asisten estudiantes, padres y madres para ofrecerse como voluntarios, los docentes lo visitan en su tiempo libre en busca de consejos que ayuden a mitigar los comportamientos de determinados alumnos. La policía local se pasa casi a diario a saludar a los menores y a jugar un rato con ellos, siendo curioso escuchar "quién me iba a decir a mí hace unos meses que iba a tener esta relación con los chavales". Al organizar la información relativa a los agentes sociales proponemos la siguiente categorización.

\section{Función comunitaria}

La información recabada nos indica que efectivamente los centros de día para menores, desde su función comunitaria, se convierten en un instrumento de transformación social positiva no sólo de sus usuarios directos sino también de vecinos, profesionales, instituciones públicas y privadas. De igual modo, la práctica está resultando innovadora, eficaz y eficiente, puesto que se están convirtiendo en punto de mira de otros municipios y entidades que ven en la experiencia una solución a algunos problemas sociales del municipio. Muestra de ello es la concesión "el semáforo verde" (mención especial que otorga el diario local del municipio de Las Gabias de Granada a iniciativas positivas) "por ser proyecto innovador y beneficioso para menores y familias más vulnerables". Distinta muestra de la acogida recibida es el comentario de la alcaldesa del municipio granadino: "Haría falta dar una rueda de prensa para que se supiera lo que se está haciendo en el pueblo", y esto no es otra cosa que el interés de un político por difundir sus éxitos en materia de atención social. Además reciben las impresiones de los ciudadanos sobre la buena aceptación que ha tenido el programa en el pueblo; "este proyecto no se puede perder, hay que mantenerlo para que se sigan beneficiando otras familias con dificultades" comentaban reiteradamente políticos y técnicos de distintas poblaciones.

El apoyo de las administraciones confirma la huella y la repercusión que están impregnando los programas de prevención en el desarrollo comunitario, centrado principalmente en factores socioeducativos y de bienestar social "nos sentimos orguIlosos de contribuir con este recurso" manifestaba la Jefa de Servicio de Igualdad y Bienestar Social de la Junta de Andalucía. Del mismo modo, en el boletín interno ${ }^{\circ}$ 26 de Aldeas Infantiles SOS del mes de octubre de 2010, en un apartado de la página 2, se recogen unas palabras de la Conselleira Gallega, referente a los centros de día: "representan hacia dónde tienen que ir los centros de menores". Ya no es sólo una huella, sino una nueva forma de entender el trabajo con niños, es un haz de luz encontrado en la oscuridad de un problema social, una esperanza real que está patente en los programas educativos de los centros de día. 
Decíamos que una de las finalidades del programa era evitar la retirada del menor y la ruptura familiar. Esta es una medida extrema que debe emplearse en situaciones extremas, así nos lo indica una técnico del servicio de protección de menores de Vigo en una entrevista "Cambiaríamos muchos centros de protección por centros de día" consciente de que si muchos niños hubieran pasado por este recurso no hubiera sido necesario emplear medidas de internamiento residencial, "... a veces me pregunto cómo protegemos a los niños, ¿los centros de protección son lo ideal? En algunos casos será irremediable, ¿pero a cuántos niños se les ha separado de su familia por no existir estos recursos?". La reflexión emanada de la entrevista es para el estudio muy significativa, entre otros aspectos porque se pone al descubierto la tibieza y el fracaso de determinadas políticas de prevención dirigidas a la infancia. Siendo así, la administración ha de hacerse eco de dicho sentir y darle un giro a las políticas de prevención y protección; numerosos agentes sociales lo reclaman: "Vigo, es una sociedad con una problemática social muy importante y no hay otros recursos que aborden y apoyen a las familias y a los niños", "llegan donde nadie Ilegan, con recursos, con programas preventivos,.../... es una pena, deberían haber más recursos como éste". Las argumentaciones de técnicos de Vigo, Zaragoza y Granada avalan ya no sólo la necesidad de su sistematización sino de su eficacia puesto que es tangible la trasformación de la realidad social de los usuarios y del entorno donde está presente; "aquí (Zaragoza) tenemos 2.600 viviendas sociales ocupadas por familias con problemática social importante, entonces al atender a los menores de estas familias, se está haciendo un gran trabajo social con estos niños; si no hubiera estos centros, aumentarían los chavales en la calle, consumo, vandalismo...", "en muchos casos se minimizan los efectos de los indicadores de riesgo, eliminarlos es difícil pero en la mayoría se mitigan como es el caso del absentismo escolar, consumos, etc.", respondían acordemente durante las entrevistas los agentes sociales de los tres centros; es la constatación del potencial educativo y social derivado del programa. En el trasfondo de estos testimonios se esconde la ilusión, la sorpresa y la alegría de haber encontrado un recurso que da respuesta a problemas que antes los embargaban.

\section{Conciliación individuo-sociedad}

De igual modo, los líderes sociales han apreciado el civismo de los menores. Las prestaciones del programa están logrado que se reduzca la conflictividad que coexistía entre los jóvenes y el medio, avenencia entre sujeto y contexto. La percepción de los ciudadanos confirma la capacidad de los centros de día para transformar patrones de comportamiento, aliviar situaciones angustiosas de familias en relación con sus hijos. Ha sido denominador común, el reconocimiento del impacto sobre el entorno comunitario: bibliotecas, instalaciones deportivas, exposiciones culturales, representaciones teatrales, fiestas populares, etc., han sido frecuentadas por nuestra población. Testifican el bibliotecario y la concejala de servicios sociales del municipio de Granada en un acto público: “...los niños del centro están sacando libros, algunos vienen hasta con sus padres, además no se retrasan en las devoluciones, ¡es inaudito!", "oye, estaba temerosa por los niños, pensaba que me iban a reventar el acto, han sido todos unos primores". Estas expresiones demuestran sorpresa, aludiendo a un antes y a un después; para el bibliotecario ya no es un problema prestar 
un servicio al menor, para la concejala es una muestra de convivencia, ciudadanía y participación social de un segmento de población de la que antes no existían garantías: para los políticos, los empeños de los centros_de día son un éxito del que se apropian en sus discursos.

Niños y adolescentes que antes se hacían notar (según informes de servicios sociales y centros educativos) por conductas vandálicas, antisociales, inadaptadas, ahora sorprenden gratamente por su comportamiento, participación, urbanidad y otras habilidades que repercuten en el entorno. En palabras de la policía local, las conductas antisociales de la población más joven se han reducido de forma notable. "quién los ha visto y quién los ve" nos decía un policía de la zona; "qué faltica estabais haciendo en el pueblo", expresaba el jefe de policía local de otro municipio, el cual colaboraba con el centro de día en materia de educación vial. Explicamos que dicha colaboración surge voluntariamente: el agente comprueba que es el momento de acercarse a este segmento de población aportando su granito de arena, y apuntamos que el policía acudía al centro incluso fuera de servicio, porque deseaba jugar al fútbol con ellos, participar de las asambleas, al punto de que en reiteradas ocasiones expresaba con satisfacción: "esto es lo que le hace falta al pueblo". Quizás Ilama especial la atención esta confesión de un agente: "ya no me ven como antes pero es que yo tampoco los veo como antes; son muy jóvenes para hacer lo que hacían, estaban tirando su futuro por la borda..." decía con un nudo en la garganta que le impedía terminar. Situados en el lugar del policía, sus palabras nos obligan a pensar que algo ha cambiado en su trabajo, en su día a día, y no es otra cosa que la de sentirse apoyado y reforzado por un programa que está logrando que los más jóvenes enderezcan sus vidas, ganando en seguridad y orgullo, su principal misión.

\section{Esperanza social cumplida}

Fue curioso apreciar que en poco tiempo, vecinos, niños y adolescentes comparaban el planteamiento educativo con una esperanza para cambiar sus vidas: desorientados por no saber cómo actuar ante situaciones asfixiantes los propios jóvenes acuden al centro en busca de una mano salvadora. "Nuestros padres han estado en los servicios sociales solicitando plaza y le han dicho que no hay plazas libres. ¿Qué podemos hacer para apuntarnos?", reparaban unos niños. "Aunque sé que no hay plazas, ¿no le podéis hacer un hueco?, es que le hace mucha falta" rogaba una madre entendiendo que el programa era la forma de salir del charco.

El acercamiento a los recursos del entorno por parte de menores y familias diríase que hacía renacer otras oportunidades como la participación cívica, la convivencia, el sentirse ciudadanos, otras esperanzas. La mesnada de niños y adolescentes con actitudes asociales se ha convertido en una referencia de jóvenes asentados, provocando un sentimiento de admiración compartido por todos los agentes sociales. Abandonada la sensación de frustración ante las previsibles conductas asociales, encontramos comentarios de políticos, profesores, policías, trabajadores comunitarios al asegurar que el programa debería estar en todos los municipios: en su opinión dificultades similares concurren en todas partes, con la particularidad de que ahora existen claves para paliar los problemas derivados de la vulnerabilidad. Llegó la hora para los maestros y profesores del desahogo profesional: "tendría que haber centros 
de día en todos los municipios"; "vuestro trabajo es esencial para sacar adelante a la juventud", "vuestro trabajo, también es un apoyo para nosotros", "el centro de día nos aporta una ayuda externa que consideramos fundamental porque la escuela y las familias no pueden desarrollarla; en cambio, en un centro de día encontramos la posibilidad de hacer todo aquello que los centros escolares no pueden". Un discurso similar mantenía la coordinadora de un equipo de orientación educativa de Zaragoza y el director de los servicios sociales de la zona "...estamos haciendo trabajos con las familias, que si no fuera por vosotros, nunca haríamos...".

Al escuchar los testimonios de los líderes sociales no se puede dejar de sentir cierta satisfacción: pareciera una justa recompensa el reconocimiento de la labor que realizan los profesionales de los centros de día, cuando se certifica que estamos en la línea deseada. Esta valoración se repite al unísono en la mayoría de los registros y entrevistas: al objeto de conseguir financiación, la Alcaldesa del municipio granadino se apresuraba a argumentar a la Vicepresidenta de la Diputación Provincial de Granada, "... este es un programa que está dando unos resultados muy positivos al municipio, vuestros propios SS.SS. dan fe del cambio de muchas familias y sus hijos; necesitamos una financiación permanente para asegurar su permanencia en el pueblo..."; "Esto es precisamente lo que le hace falta...". Los éxitos del programa se han ocupado de hacer lo importante, no sólo en los menores, sino también en el entorno social.

\section{Creación de nuevas oportunidades de desarrollo comunitario}

A los activos mencionados se suma el colectivo de empresarios; aunque reconocemos que en primera instancia se sentían reacios, la estela del programa ha generado colaboración a través de la prestación de sus instalaciones para la realización de algunas experiencias educativas. No han tardado en darse cuenta que vale la pena arrimar el hombro a la causa: "tengo una amiga que es bailaora, y muchos de sus espectáculos los dedica a recaudar fondos para fines benéficos. Le he hablado de vosotros y en su próximo espectáculo, desea contribuir con el recurso". Es la apuesta de un empresario para apoyar la labor social del programa educativo. Mirando al futuro otro dejaba entrever su preocupación: "el miedo que me da es que el día que os vayáis volvamos como al principio," ilustrando un punto y aparte en la dinámica social del entorno. En algunos lugares, ha sido emotivo encontrar buena acogida hacia el planteamiento educativo que presentamos porque no sólo se ofrecían descuentos a los materiales del centro sino que nos regalaban una gran sorpresa: ofrecer empleo a padres y madres. Con la misma voluntad, una empresaria extranjera ofrecía su colaboración, con la voz entrecortada y dificultad para hablar testimoniaba: "si mi hijo hubiera tenido esta oportunidad no estaría donde está ahora", realmente no sabemos su paradero, pero por su expresión aseguramos que no debe ser un buen sitio. Las manifestaciones presentadas arrojan indicadores de solidaridad por un lado y por otro el convencimiento de que pueden contribuir al resurgir de nuevas oportunidades y la apertura a otras coyunturas que impulsan el desarrollo de la ciudadanía.

Cuando se decide titular el artículo con el término de 'impacto' es porque efectivamente el programa en sus inicios no contemplaba estos efectos sobre el entorno; ha sido algo inesperado que ha surgido de unas actividades vinculadas a la validación 
del programa de los centros de día como recurso de integración social. Hay que destacar su relevancia en el ámbito comunitario. Después de un tiempo los centros de día se integran en el entorno y el entorno asimila su filosofía: muestra de ello es la complicidad entre agentes sociales, menores, adolescentes y familias en riesgo de exclusión social.

\section{Conclusiones}

Los agentes sociales participantes han hablado: en los centros de día se encuentra un programa eficaz e integrado en la red de servicios de una zona. La iniciativa es un instrumento de desarrollo socio-comunitario por cuanto logra la dinamización e integración de profesionales e instituciones en su afán por mejorar la vida de las personas y contribuir al equilibrio social. Es por ello que el impacto de los centros de día en la sociedad descubre nuevos encuentros y restaña viejas suspicacias entre colectivos sociales. En consonancia con las aportaciones recordadas nos parece oportuno reseñar a:

Usuarios directos: la repercusión de las intervenciones realizadas con menores y familias se han vertido en la dinámica social del entorno, se han reducido los estigmas sociales y se ha favorecido la integración de colectivos, contribuyendo a una mayor optimización y dinamización de estratos.

Vecindario: los vecinos, han visto en el proyecto un instrumento de prevención e integración, toda vez que en su apreciación despeja un riesgo social en el trabajo con niños. Lo aprecian como una forma de cuidar, proteger y educar a sus hijos, aunque éstos no pertenezcan al centro.

Instituciones: centros educativos, residencias de mayores, centros de salud, las Delegaciones de Igualdad y Bienestar Social de la Junta de Andalucía, Xunta de Galicia y el Gobierno de Aragón, bibliotecas y otras instituciones y servicios del entorno consideran los resultados del programa como activos tanto de apoyo y desarrollo social cuanto de promoción profesional.

Ayuntamientos: las municipalidades han tenido que rendirse ante el descenso de la problemática de sus vecinos y la recuperación de la tranquilidad en la calle.

Sin embargo, pensamos que el mayor impacto social que se ha producido ha sido el cambio de visión que ha suscitado en los ciudadanos la problemática infantil y la de sus familias, reduciendo notablemente los estigmas personales y creyendo que es posible la transformación social y personal si se cuentan con los recursos y mecanismos adecuados. Los agentes sociales han encontrado un aliado profesional, una oportunidad de desarrollo comunitario que optimizan sus trabajos y estimula el compromiso social que han de tener como ciudadanos. La investigación pone al descubierto el potencial educativo y la rentabilidad social que ostentan los denominados centros de día de atención a menores en los entornos que cuentan con su presencia.

En síntesis, a nuestro modo de entender el tema, la propuesta de los centros de día es un revulsivo potente confiando que sus programas proliferen; su expansión territorial está en manos de políticos, técnicos, docentes, empresarios, vecinos al disponer de nuevas técnicas y solicitar decisiones en esta dirección..., ellos pueden contribuir a que la sociedad sea una sociedad un poco menos excluyente y los líderes sociales algo más optimistas. 


\section{REFERENCIAS BIBLIOGRÁFICAS}

AYERBE ECHEBARRÍA, P. (1991). Pedagogía de la marginación social. Madrid: Popular.

Boletín interno de Aldeas Infantiles SOS España, 26, octubre de 2010, 2.

BUENO BUENO, A. (Coord.) (1996). Intervención social con menores. Fundamentación y programas de la comunidad valenciana. Alicante: Universidad de Alicante. Fundación Cultural CAM.

CASAS AZNAR, F. (1998). Las situaciones sociales de riesgo: la prevención de los problemas sociales en la infancia. Barcelona: Paidos.

CASTELLÓ, M. (2005). La hora del café: una experiencia de trabajo con padres y madres desde un centro abierto. RES. Revista de Educación Social, 4, Infancia y Educación social. Disponible en: http://www.eduso.net/res/?b=7\&c=55\&n=148.

Decreto 27/2003, de 21 de enero, de la atención social primaria. DOGC, 5 de Febrero de 2003, núm. 3815, p. 2066.

GARCÍA MíNGUEZ, J. y SÁNCHEZ RAMOS, J.M. (2010). Centros de Día de atención a menores: competencias del educador social como figura de referencia. Revista Historia de la Educación Latinoamericana, 15, 125-146.

GONZÁLEZ MENÉNDEZ, A.; FERNÁNDEZ HERMIDA, J.R. y SECADES VILLA, R. (coords.) (2004). Guía para la detección e intervención temprana con menores en riesgo. Gijón: Colegio Oficial de Psicólogos.

GONZÁLEZ SALA, F. (2006). Estudio de los perfiles de las familias en situación de riesgo social: programas de ayudas P.E.R. y P.E.P. del Ayuntamiento de Valencia. Valencia: Universitat de València. Disponible en: http://www.tdr.cesca.es/TESIS_UV/ AVALAIBLE/TDX-0103108-101658//gonzalez.pdf [Fecha de acceso: 16/10/2009]

LABRADOR, C. (2006). Las instituciones y agentes de Educación Social desde el siglo XVI al XIX. En A. Tiana Ferrer y F. Sanz Fernández (coords.), Génesis y situación de la Educación Social en Europa. Madrid: UNED.

LIZÓN GARCíA, A. (2001). Los Centros de Día. En M. Pelegri Roselló (coord.), Los Centros de Día como recurso de atención a la infancia, pp. 279-289. Madrid: Comunidad de Madrid. Consejería de Servicios Sociales.

MONDRAGÓN LASAGABASTER, J. y TRIGUEROS GUARDIOLA, I. (2004). Intervención con menores. Acción socioeducativa. Madrid: Narcea.

MONTRAVETA, I. Situaciones de Riesgo Social. Revista de Política Social y Servicios Sociales, 9. Citado en J. Mondragón Lasagabaster y I. Trigueros Guardiola (2004), Intervención con menores. Acción socioeducativa (pp. 59-60). Madrid: Narcea.

MORENO, A. (2005). El centro abierto y la UEC: recursos para la infancia y adolescencia en situación de riesgo social en Barcelona. RES. Revista de Educación Social, 4, Infancia y Educación social. Disponible en: http://www.eduso.net/ $\mathrm{res} / \mathrm{?} \mathrm{b}=7 \& \mathrm{c}=55 \& \mathrm{n}=183$.

MUSITU OCHOA, G. et. al. (2004). Familia y adolescencia: un modelo de análisis e intervención psicosocial. Madrid: Síntesis.

ORTEGA ESTEBAN, J. (coord.) (1999). Educación Social Especializada. Barcelona: Ariel Educación. 
PELEGRI ROSELLÓ, M. (coord.) (2001). Los Centros de Día como recurso de atención a la infancia. Madrid: Comunidad de Madrid. Consejería de Servicios Sociales.

PÉREZ SERRANO, G. (1994). Investigación cualitativa. Retos e interrogantes. Vol. I. Métodos. Madrid: La Muralla.

PÉREZ SERRANO, G. (1994). Investigación cualitativa. Retos e interrogantes. Vol. II. Técnicas y análisis de datos. Madrid: La Muralla.

QUINTANA CABANAS, J.M. (1998). Pedagogía Social. Madrid: Dykinson.

ROSINACH, E. (2005). El centro abierto: un espacio humano, plural y diverso. La intervención socioeducativa en un centro abierto. Revista de Educación Social, 4, ejemplar dedicado a Infancia y Educación social. Disponible en: http://www. eduso.net/res/?b=7\&c=55\&n=165.

SÁNCHEZ RAMOS, J.M. (2012). Un recurso de integración social dirigido a menores en situación de riesgo. Los centros de día de atención a menores. En A.S. Jiménez Hernández, Menores en contextos de riesgo. Estudios y reflexiones sobre prácticas educativas (pp. 47-55). Huelva: Joxman.

VECINA MERCHANTE, C. y BALLESTER BRAGUE, L. (2012). Trabajo en red: Optimización de las intervenciones socioeducativas con menores. En A.S. Jiménez Hernández, Menores en contextos de riesgo. Estudios y reflexiones sobre prácticas educativas (pp. 75-84). Huelva: Joxman.

VEGA, AMANDO (1989). Pedagogía de inadaptados sociales. Madrid: Narcea. 